\title{
The Effects of a Non-polar Surfactant on the Crystallization Behavior and Physical Properties of the High-Melting Triglyceride Fraction of Milkfat
}

\author{
J.W. Litwinenko, A.G. Marangoni* \\ University of Guelph, Department of Food Science, Guelph, ON, Canada, N1G 2W1 \\ * Author to whom correspondence should be sent
}

The texture of foods that are high in fat, such as butter, can be dramatically altered by crystallization conditions and the presence of minor polar components [1]. The effects of non-polar surfactants on emulsion properties have been extensively studied, but little is known about their effects on singlephase fat systems. In this study, the effects of the surfactant Tween60 (at levels between 0\% and 3\% $\mathrm{w} / \mathrm{w}$ ) on the crystallization of a model plastic fat system were investigated. The model system was composed of milkfat's high-melting triglycerides diluted in triolein at a 30:70 (w/w) ratio. These high melting triglycerides solidify first upon supercooling, and hence play a major role in determining the resulting crystal network structure and rheological properties.

The effects of Tween addition on rheology were profound, including a sharp increase in breaking force at $0.1 \%$, followed by a decrease at $0.5 \%$ Tween as shown in Fig. 1. Differential scanning calorimetry showed no differences in melting shape or peak melting temperatures, while NMR showed no differences in solid fat content (SFC). It was thus hypothesized that changes in rheological properties were due to changes in microstructure. Crystallization kinetics were characterized using the Avrami model. This analysis yields two parameters - a rate constant of crystallization (k) and a growth mode exponent (n). SFC curves at $28^{\circ} \mathrm{C}$ allowed for the computation of $\mathrm{n}$ and $\mathrm{k}$, which predicted maximum and minimum rates of nucleation and crystal growth at $0.1 \%$ and $0.5 \%$ levels respectively. Lower Avrami exponents (n) were found at levels associated with higher rates of nucleation and growth, and suggested less spontaneous nucleation at $0.5 \%$. Induction times and rates of crystallization determined by turbidimetry corresponded to the predictions of the Avrami model, with shorter induction times found at $0.1 \%$. Polarized light micrographs and image analysis revealed that at the $0.1 \%$ level, the crystals that made up the network were about two times smaller, and four times more numerous than at $0.5 \%$ (Fig 2). Fractal dimensions remained constant $(\sim 2.0)$ indicating no change in the spatial distribution of the network and suggesting that differences in breaking force were primarily due to particle properties. This is consistent with the predictions of the Avrami model, trends in the storage modulus and induction times, and our knowledge of crystallization in general (with shorter induction times resulting in more spontaneous nucleation, smaller and more numerous particles, and a more rigid network). Timelapsed microscopy allowed for the visualization of the kinetics of crystallization and the normalized percentage of crystal mass was plotted against time yielding crystallization curves that showed the same relative differences in both induction times and rate of crystal growth as found by NMR and turbidimetry. The role of PLM in corroborating the results of previous experiments vastly enhanced both the qualitative and quantitative findings of the study.

\section{References}

[1] A..J. Wright, J. Am. Oil Chemists' Soc. 7 (2000) 463. 


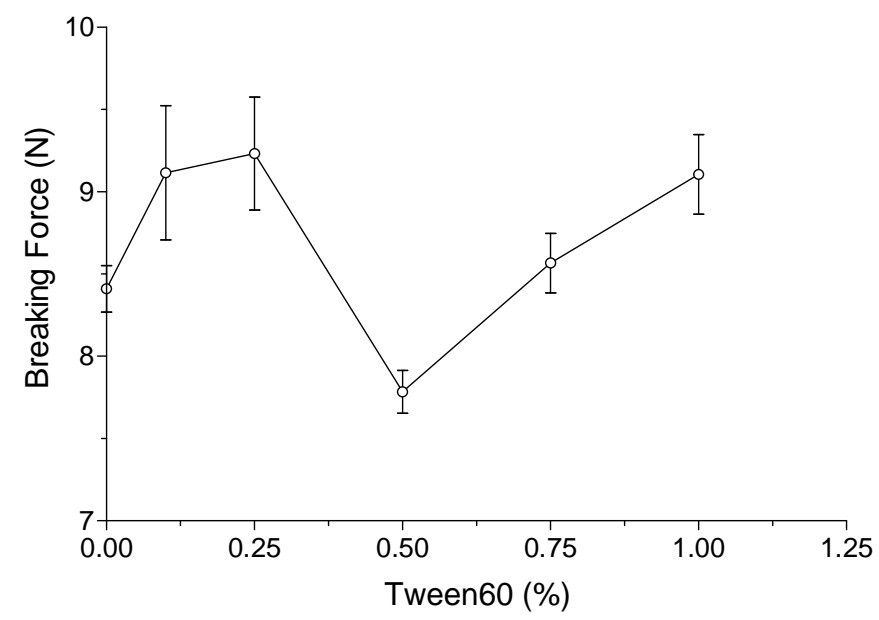

FIG. 1. Breaking force (N) as a function of Tween60 added (\%) to 70:30 triolein:HMF following storage at $5^{\circ} \mathrm{C}$ for $24 \mathrm{~h}$. Samples were compressed beyond fracture by parallel plate compression at a crosshead speed of $10 \mathrm{~mm} / \mathrm{sec}$ using a $5 \mathrm{~kg}$ load cell.
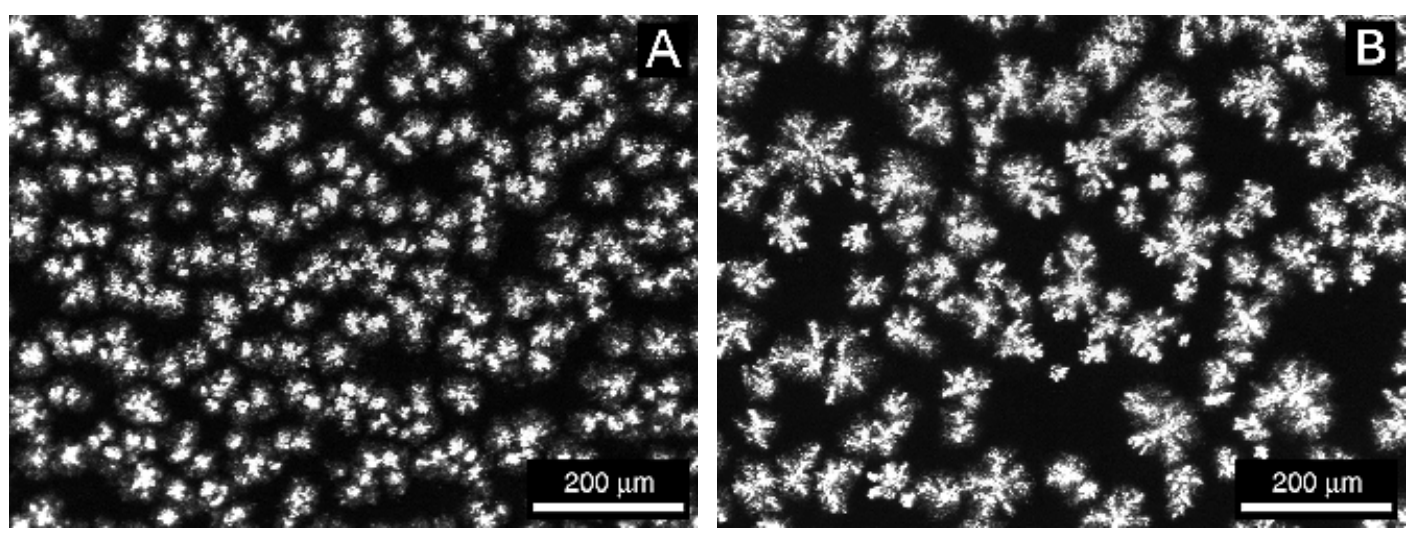

FIG. 2. A) Polarized light micrograph of $70: 30$ triolein:HMF with $0.1 \%$ Tween 60 after 15 minutes at $28^{\circ} \mathrm{C}$. B) Polarized light micrograph of 70:30 triolein:HMF with 0.5\% Tween60 under the same crystallization and storage conditions as A.

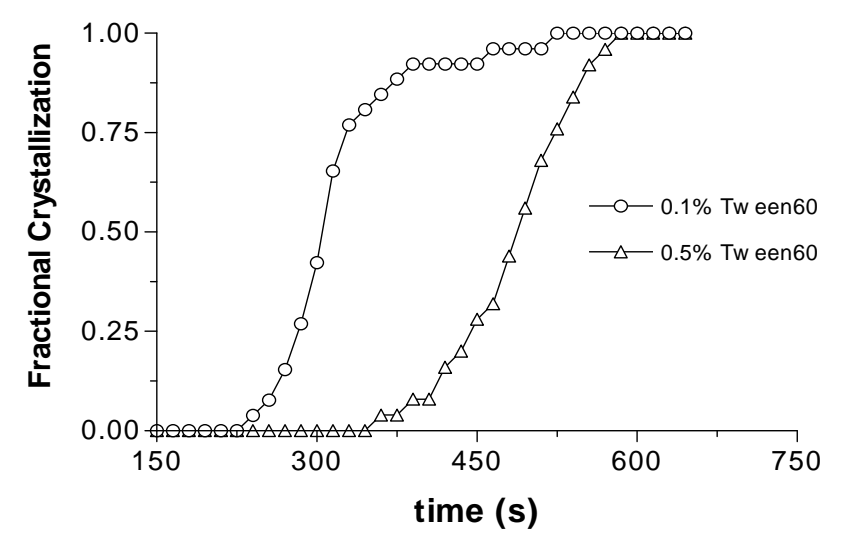

FIG. 3. Fractional crystallization as a function of time for samples of 70:30 triolein:HMF with $0.1 \%$ and $0.5 \%$ Tween 60 added. Fractional crystallization was designated as the percentage of crystal mass relative to the final mass attained, determined by \% black upon thresholding. 